THE MASON'S ELEVATOR HANDLING MACHINE

\author{
Dieter Böhm \\ Modern Technik
}

Modern Technik, Wilfried Bäder GmbH \& Co. KG Maschinenbau, Staffelstr.21, w-7305 Altbach

\title{
THE MASON'S ELEVATOR HANDLING MACHINE
}

During a lecture given on the eve of the 1985 BAUMA Exhibition in Munich, participants learned that

- about $90 \%$ of all tunnelling work,

- about $60 \%$ of all earth-moving, civil engineering and highway construction work,

- but only $40 \%$ of construction and residential building work

are mechanized. The question was raised as to whether mechanization could help to humanize working conditions in the building construction industry.

These figures induced MODERN TECHNIK to intensify its work on the concept of a robot or bricklaying machine which had been taken up in 1984, and to design a machine capable of bringing benefits to all concerned in the building industry. 
Stationary machines to produce masonry panels are mainly suitable for companies which are at one and the same time the building sponsor and building contractor and are thus able to adapt the overall project planning to the needs of the production facility. On-site assembly of the masonry panels necessitates a sophisticated logistics chain between the manufacturing and building sites; in addition to the capital investment in the production machinery, high costs are also incurred for means of transport and use of suitable lifting equipment. In urban areas, time problems may also be encountered because of traffic density.

The robots already used in industry were considered as models for a bricklaying machine. Perusal of the relevant documents showed that technical problems ruled out for the time beeing any possibility for us to build an automatic machine to lay masonry blocks on different sites with varying architecture, and also that the cost would be too high to permit economic use of such a machine.

Nevertheless, MODERN TECHNIK took up the idea of one type of robot design and built a semi-automatic machine on which the bricklayer sat in a cabin and used positioning levers to control the movements of the semi-automatic machine. To ensure simultaneous coordination of all the movements necessary for correct placing of the block, the operator had to actuate hand levers and foot switches simultaneously; this placed demands on him which exceeded the possibility of human reaction. 
Dimensional problems also arose. The higher the wall, the more inaccurate the length and height dimensions became. As a result, this project too was abandoned. After further research, MODERN TECHNIK came to the conclusion that attention must be focussed on the human operator who has to control a machine which will enable him to work more easily and quickly, and is at the same time easy to operate; that was the origin of the MASON'S ELEVATOR HANDLING MACHINE (MEHM).

The MEHM is a platform with hydraulic vertical adjustment, running on eight dual wheels with an electrical drive; it is controlled from the bricklayer's workplace. The masonry blocks and mortar are stored on the platform (Fig.1).

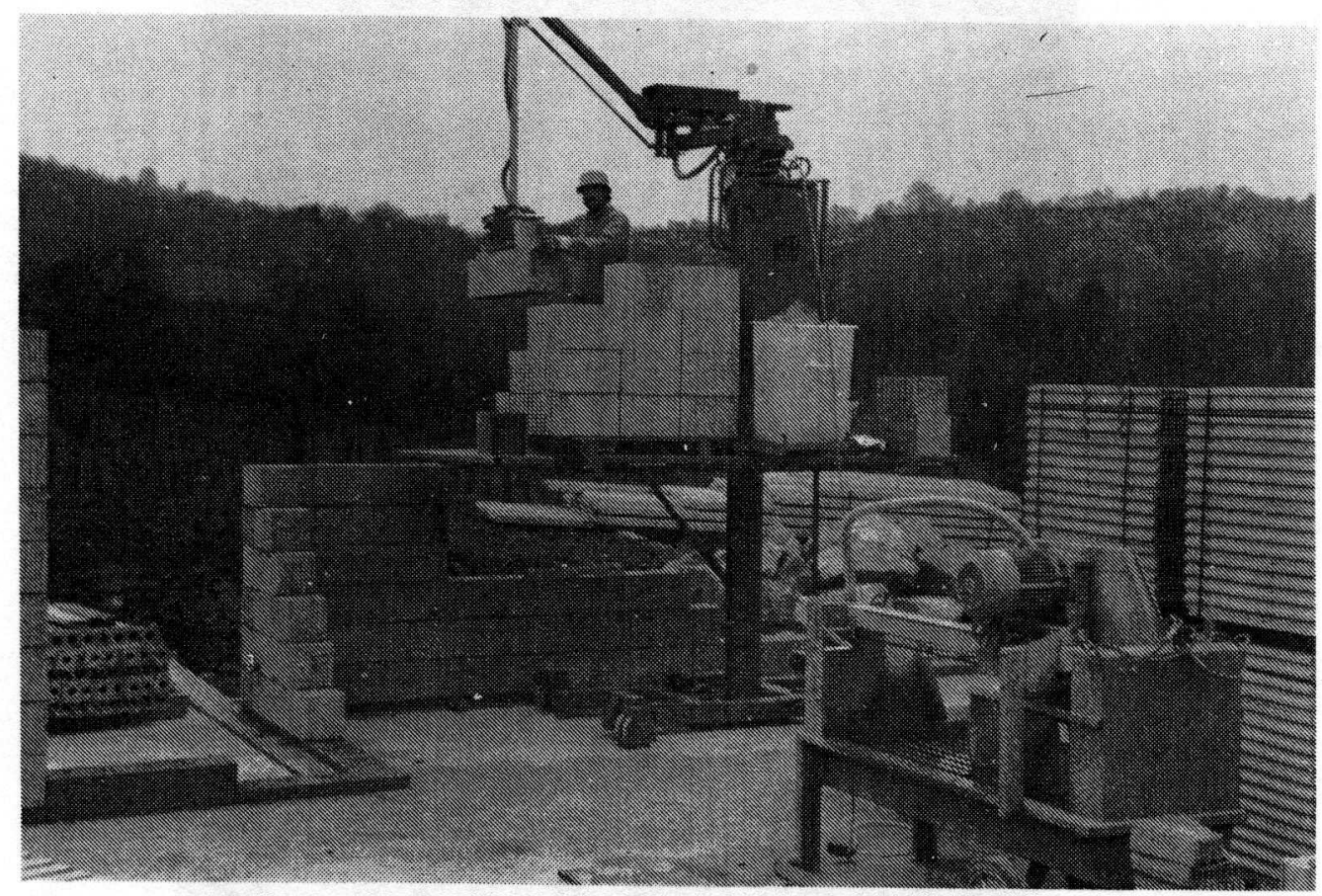

Figure 1: The MEHM in action at the construction site

The handling unit lifts blocks with a total weight of $120 \mathrm{~kg}$ individually or in pairs, and the bricklaying 
unit then positions these blocks accurately and smoothly. Pneumatic weight compensations ensures that the clamp can be stopped in any position. A vibrator built into the clamp taps the blocks onto the layer of mortar. As a result of the mobility of the platform along the wall which is being constructed, the handling range of the clamp $-30 \mathrm{~cm}$ to $350 \mathrm{~cm}$ when use is made of the infinitely variable vertical adjustment of the platform amounting to between 30 and $170 \mathrm{~cm}$ - the bricklayer always has a correct and fatigue-free working position, and is able to lay large blocks continuously throughout the working day with a low physical effort (Fig. 2, Fig. 3).

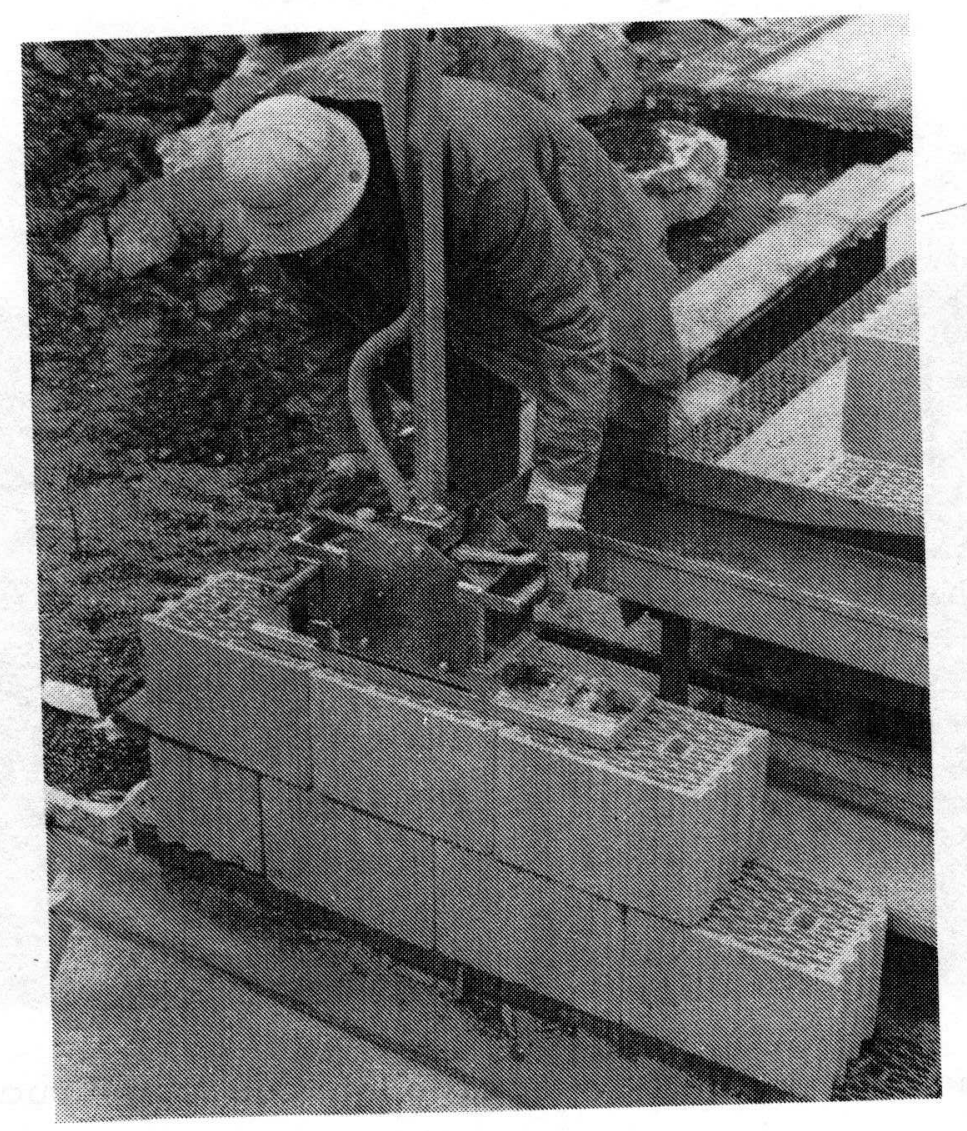

Figure 2: Handling blocks with the MEHM 


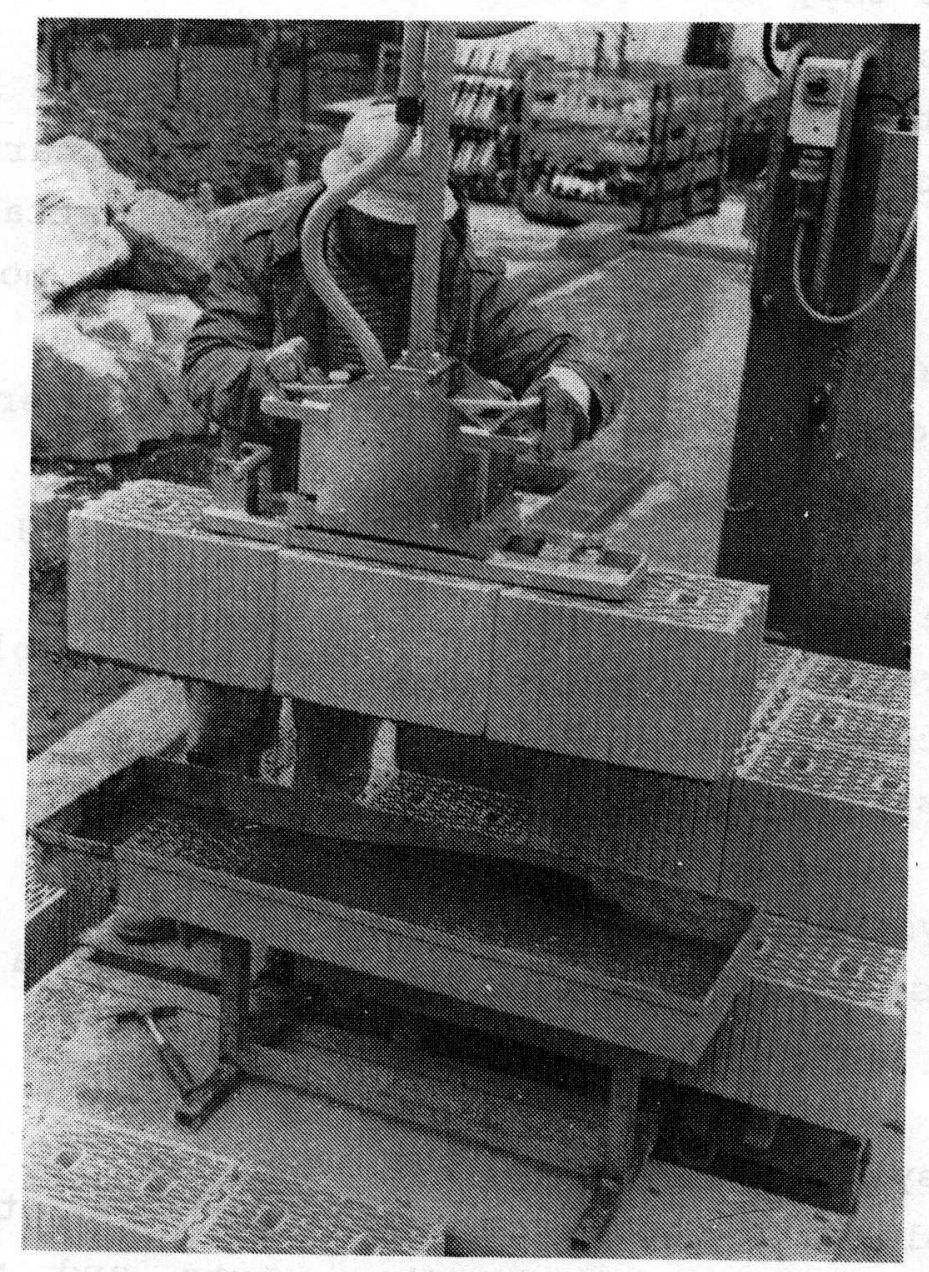

Figure 3: Dipping blocks into mortar before setting them onto the growing masonry

The machine meets the requirements of the building trade federations from the angle of health standards. The MEHM is not a machine in the strict sense of the term, but a workplace for the bricklayer which consists of:

- a steerable platform which travels on the floor;

- a vertically adjustable lifting platform; 
- a handling unit which grips the masonry blocks so that they can be moved easily without strenuous effort;

- a storage position for the blocks to be layed;

- a mortar pump with a hose arm and mortar sledge; or, as an alternative, an ergonomic attachment for the ready-mixed mortar through with a mortar paddle;

- holders for the spirit level, bricklayer's trowel and hammer;

- safety band shears to cut the packaging band from the masonry blocks;

- a refuse bin for the wrapping band or block packaging material;

- a spray device to wet the blocks.

The system also includes CORNER BOARDS to lay the corners with triple aligning cords and a ready-mixed mortar trough carriage.

This system eliminates the need for the bricklayer's scaffold with the accompanying purchase, transport and erection costs; scaffolding parts and planks lying around on the floor are a thing of the past.

If effective use is to be made of the MEHM, bricklaying cannot be treated as an isolated operation; on the contrary, the building project must be considered as a single entity in its own specific environment.

To permit economic use of the system, everyone involved in the masonry construction work must participate:

- the architect

- the masonry block manufacturex

- the building contractor

- the employee 
The ARCHITECT must be made aware of the existence of a system which enables large masonry blocks to be layed in a mechanized manner and with less strain on the mason, thus making for greater economy; he no longer needs to include smaller building blocks in his calls for tender. He should plan the masonry construction work jointly with the building owner in such a way that e.g. window and door openings are designed to enable whole blocks to be layed to avoid the need to cut single blocks and thus help to keep costs down.

The MASONRY BLOCK MANUFACTURER should in future deliver stones in a suitable state for immediate laying. Today some blocks reach the site in a condition in which they are not ready for immediate laying; the mason has to handle each block twice to enable it to be layed, and that takes time. The building contractor cannot calculate the time needed in advance - but time costs money.

Manufacturers of building blocks are capable of supplying their material in a fit state for immediate laying, but they do not do so because the building contractors do not specify this requirement; and so they save costs which are then incurred by the building contractor who has to handle the blocks twice. Companies which work with our system order their blocks from manufacturers who supply them ready for laying, even if the purchase costs are somewhat higher. These fixed costs can be calculated accurately by the building contractor, unlike the time taken to present the blocks for placing.

Building block manufacturers who offer their blocks ready for laying are able to achieve higher turnover levels. 
The BUILDING WORKER must be given to understand that

- he will not be replaced by this system

- will not have to lay his masonry blocks quicker, and

- will not be downgraded into a machine operative

but will on the contrary

- be able to work with less physical effort

- decide his working rate for himself

- be the focal point of the system.

It must be made clear to the bricklayer that he will still have to lay the blocks despite the introduction of the machine; but he will have a lifting aid at his disposal which makes his work less strenuous and safeguards his health.

Industrial workers have to engage in physical exercise after their working shift to become tired- but that is certainly not the case for skilled manual workers in the building trades. The building contractor must make it quite clear to his employees that he will still need them for a long time and will not be pensioning them off early - because trainee bricklayers are hard to find.

For the BUILDING CONTRACTOR, the purchase of an MEHM with its accessories means an investment which must be calculable. When analysing the acquisition, he must not think only of the purchase cost, but also ask what advantages the purchase of an MEHM will bring. 
In addition to faster and less expensive laying, it also brings him

1. greater prestige with architects and clients through the use of the latest technology;

2. cost savings through fewer absences of his staff attributable to occupational illnesses, such as back pains and intervertebral disk lesions;

3. the possibility of offering his masons a genuine workplace, and

4. more work for himself and his senior staff through the acquisition of more building contracts and reorganization of the construction process.

The remarks which follow are not meant to be representative of all building companies, but do hold good for some of the companies questioned by MODERN TECHNIK.

Point 1: "Greater prestige with architects and building owners"

Building contractors tend to work mainly with their regular architects who place work with them. They treat enquiries from unknown architects with great scepticism, because they suspect that these are mostly used to draw comparisons with their colleagues. contractors therefore construct buildings which correspond to their machine stock, scale of their company and number of staff on the basis of contracts received from their architect. They tend not to advertise very much for their company. One way of offering their services might therefore be to: 
Prepare an advertising leaflet dealing with their company and its personnel, machinery and equipment, placing particular emphasis on the use of the latest technology for masonry work, and also emphasizing their ability to meet building deadlines and to work quickly; this brochure could then be circulated to architects.

This offer of greater performance and ability to meet deadlines brings with it the prospect of winning more lucrative contracts. The building contractor must himself approach the market.

Use of the MEHM requires a clean building site. To permit mobility of the platform, the floor must be swept clean and not used as a place to store materials or equipment. A clean building site means a better image for the contractor with his customers.

Point 2: "Fewer occupational illnesses"

Personnel absences because of illness cost a great deal of money. It is not only necessary to go on paying their wages; replacement of the sick employee by another costs money, and also reduces the ability of the contractor to complete another building project on time. Use of the MEHM helps to reduce the frequency of the occupational illness.

Point 3: "Offering a workplace"

Young people who present themselves for a training place in industrial companies may be given a file, a handsaw and a triangular scraper as their basic tools, but the trainer will already be able to show them a modern and technically sophisticated workplace when they make their application, e.g. a CNC machine which the trainees will be called upon to use later. 
Building contractors provide young trainee bricklayers with a hammer, spirit level amd mason's trowel. Once they qualify, their working tools remain the hammer, spirit level and trowel. To use experienced masons as machine drivers on building sites is too expensive and it makes no sence to use them in that capacity. Nowadays young people have their own video recorder and personal computer and are open to technical developments. If the building contractor is able to offer interested young persons after their training a workplace which involves electrical, hydraulic and pneumatic systems, he will probably find it easier to conclude a training contract than under the circumstances prevailing today.

Point 4: "More work for the building contractor"

An outsider looking at a building site today will be struck by all the personnel moving around on the site. Masons have to walk away from the wall they are building to fetch blocks or mortar; they must go from one corner to another in order to raise the aligning cord and sometimes have to search for tools which they have left lying somewhere else. All this walking around costs money and should be avoided as far as possible. When an MEHM is used, certain adjustments should therefore be made to the planning and production arrangements.

Before the bricklaying work begins, a plan of the actual work should be drawn up and the entire bricklaying operations divided into partial segments, such as laying the first layer, precise definition of door and window openings and possible division of the building team into groups. 
The ideal solution has been found to consist in the division of the building team into a concrete and formwork group, a masonry group and a supervisory group.

The concrete and formwork group builds from the basement to the first floor screed and then moves away to another site.

The masonry group builds the walls and moves on to the second site which will by then have reached the level of the first floor screed; it goes on to erect the walls on this site, while the first group in its turn lays the second floor screed on the first building site. These two groups alternately construct two buildings next to each other. The supervisory team monitors progress of the construction work. This procedure requires good advance planning; it also needs more orders for construction work because of the increased building capacity.

When an MEHM is used, a two-man team has proved to be the most productive. One mason lays the blocks with the MEHM, the employee with the most experience being responsible for organization and logistics. He coordinates the work, lays the first layer of masonry and places the masonry corners; he aligns the cords, saws the blocks to shape, is responsible for the mortar, and transports the blocks onto the working platform at the right time using the radio-controlled crane.

The colleague who actually lays the blocks does not leave his workplace on the MEHM; everything is brought to him. This division of labour in the two-man team results in an enormous increase in capacity. 
A further increase in performance is achieved by the use of a mortar pump with a hose arm and mortar sledge on the platform itself.

It is human nature for a mason to simply use up the mortar which he has near him as the end of his working shift approaches, even though he would in reality still have enough time to prepare fresh mortar. But the mason does not prepare a new skip because he does not want to begin work next day with a half-full skip. The mortar pump enables still more productive use to be made of the available working time by accurate and careful topping up.

Use of our system creates a much better working spirit among employers and employees alike.

Through the humanized and mechanized laying of large building blocks with less strenuous effort, the employee performs better and suffers less strain on his health. This avoids absences due to occupational illnesses such as back pains and intervertebral disk lesions. Rationalized working methods bring the employer higher added value through better procurement, planning and supervision despite his capital investment costs and extra work.

The human operator is the focal point of this system and remains responsible for its economic viability. The acquisition of the workplace for a mason cannot be viewed as a short-term investment; the costs incurred must be distributed over the longest period permitted by the relevant tax regulations.

The cost of the mason's workplace is about 50.000 DM. If that cost is spread over 4 years with 10 months use per year, an hourly rate of less than 8 DM can be calculated for a 40 hour working week excluding 
interests costs, allowance for depriciation and possible repair costs. This does of course require a very good rate of capacity utilization, which in turn presents a challenge to the contractor.

It is hard to obtain precise data on the masonry laying capacity which has been achieved in practise by building contractors. But one such contractor has achieved an hourly capacity of almost $4 \mathrm{~m}^{3}$ over an 8 hour day when laying 16 DF lime sand bricks.

Attainment of that performance does, however, presuppose optimal advance planning, good logistics and above all a good working spirit on the part of everyone involved in the building project.

Finally, here is a comment by one employee:

Four weeks ago I could have broken your neck when my boss presented me with a machine like this; today I could not manage without it.

and a comment by an employer:

When I heard that my colleague was using three machines of this kind, I thought he must either be off his head or have money to burn; today I too already have two MEHMs. 